\title{
Com quantos autores faz-se uma Cidade Nova?:análise da produção existente sobre os aspectos urbanos da cidade de Natal
}

\author{
How many authors makes up a New City?: \\ analysis of existing production on the urban aspects of Natal city
}

\section{Gabriela Fernandes de Siqueira}

Universidade Federal do Ceará-UFC - Fortaleza - Ceará - Brasil

\begin{abstract}
$\longrightarrow$
Resumo: O objetivo deste artigo é realizar uma análise dos trabalhos produzidos sobre aspectos urbanos da cidade de Natal (Rio Grande do Norte), destacando tanto as produções de historiadores quanto os trabalhos de arquitetos, urbanistas e de outras áreas afins. Também se pretende traçar um perfil dos estudos urbanos, fundamental para entender os marcos e problemáticas que fizeram parte do campo da história urbana enquanto área de conhecimento, que foi consolidada principalmente a partir da segunda metade do século XX. Em relação aos trabalhos sobre a realidade urbana de Natal no início do século XX, pretende-se enfatizar as produções que destacaram elementos referentes ao terceiro bairro da cidade, o bairro Cidade Nova, criado em 1901 mediante um contexto de transformações urbanas, sociais e políticas na capital norte-rio-grandense. Diante da importância do processo de idealização e concretização do bairro Cidade Nova para a história da Natal, objetiva-se investigar como as produções locais mencionaram o processo de construção e de ocupação do referido bairro.
\end{abstract}

Palavras-chave: Aspectosurbanos. Natal.Cidade Nova.

Abstract: The objective of this paper is analyze the works produced on urban aspects of the city of Natal (Rio Grande do Norte), highlighting both the productions of the works of historians and architects, urban planners and other related fields. It is also intended to draw a profile of urban studies, critical to understand the milestones and issues that were part of the field of urban history as a field of knowledge, which was consolidated mainly from the second half of the twentieth century. Regarding the work on the urban reality of Natal in the early twentieth century, it is intended to emphasize the productions that highlighted elements for the third neighborhood of the city, the Cidade Nova district, created in 1901 by a context of urban transformation, social and political in capital of Rio Grande do Norte. Given the importance of the process of idealization and implementation of the Cidade Nova neighborhood to the history of Natal, the objective is to investigate how local productions mentioned the process of construction and occupation of that district.

Keywords: Urbanaspects. Natal. Cidade Nova. 


\section{Introdução}

O objetivo deste artigo é realizar uma análise dos trabalhos produzidos sobre aspectos urbanos da cidade de Natal, destacando tanto as produções de historiadores quanto os trabalhos de arquitetos, urbanistas e de outras áreas afins. Também se pretende traçar um perfil dos estudos urbanos, fundamental para entender os marcos e problemáticas que fizeram parte do campo da história urbana enquanto área de conhecimento, que foi consolidada principalmente a partir da segunda metade do século $X X$.

Em relação à análise dos trabalhos que analisam aspectos urbanos da cidade de Natal, pretende-se dar ênfase aos que destacaram algum elemento da história do terceiro bairro da cidade, o bairro Cidade Nova. O bairro Cidade Nova, oficializado em 1901 por meio da assinatura da Resolução n.55, publicada no jornal oficial do Partido Republicano Federal do Rio Grande do Norte em janeiro de $1902^{1}$, tornou-se território oficial da cidade por meio de uma intervenção do poder municipal em parceria com o governo estadual, e foi representado nas fontes oficiais, nas leis e decretos dos poderes estadual e municipal, nas mensagens de governadores e relatórios de intendentes que integraram o poder local no início do século XX, como local promissor. Região saudável, salubre, perto do mar, propiciadora de um ambiente idílico, em que os bons ares vindos do mar circulariam nas propriedades construídas, respeitando os ideais de salubridade e dehigienismo vigentes no período ${ }^{2}$.

Cidade Nova era exaltada pelo discurso local como um bairro capaz de representar a nova condição política do Rio Grande do Norte e de sua capital no contexto republicano, remodelando a cidade que, segundo esse mesmo discurso, iniciou o século XX ainda envolta por características

\footnotetext{
${ }^{1}$ A REPUBLICA, Natal, 04 jan. 1902.

${ }^{2}$ Para problematizar as questões referentes à construção e à ocupação do bairro Cidade Nova, ver: SIQUEIRA, Gabriela Fernandes de. Por uma "Cidade Nova": apropriação e uso do solo urbano no terceiro bairro de Natal (1901-1929). Dissertação (Mestrado em História). Programa de PósGraduação em História, Universidade Federal do Rio Grande do Norte (UFRN), Natal, 2014.
}

provincianas, com ruas estreitas, tortuosas, com bairros que alagavam, com uma configuração espacial confusa, que misturava funções diversas. A planificação de Cidade Nova demonstrava o interesse do poder local voltado para criar uma área preferencialmente, embora não exclusivamente, residencial, com novos padrões para construções de moradias. As casas não deveriam ser assobradadas, sem espaçamento entre si, como as residências existentes em Cidade Alta e Ribeira, os outros dois bairros existentes na cidade no início do século $X X$. Regras deveriam ser seguidas.

O novo bairro também seria ocupado por determinadas instituições como cafés, clubes, associações, hotéis, praças, equipamentos com funções pedagógicas capazes de auxiliar na formação daquele grupo, difundindo comportamentos e criando valores, contribuindo ainda mais para o estreitamento de laços entre os mais abastados e influentes. Atualmente, se observamos a configuração espacial dos bairros Tirol e Petrópolis, que no início do século $X X$ compunham um único bairro, a Cidade Nova, é possível notar como algumas características planejadas pelo poder municipal desde a Resolução n. 55 ainda permanecem nessa área de $\mathrm{Natal}^{3}$. As ruas esquadrinhadas em forma de grelha com nomes de presidentes da República sendo cruzadas por ruas com nomes de rios do Rio Grande do Norte foram mantidas, ou seja, o traçado urbano original foi preservado. Esses dois bairros também ainda são considerados áreas importantes da cidade, nas quais o metro quadrado continua sendo um dos mais valorizados da capital norte-rio-grandense, enfrentando até mesmo um intenso processo de especulação imobiliária ${ }^{4}$.

\footnotetext{
${ }^{3}$ É válido destacar que o bairro em toda a sua extensão foi denominado de Cidade Nova até 1947, sendo dividido oficialmente nos bairros Petrópolis e Tirol somente nesse ano. Ver: NATAL. Câmara Municipal. Projeto de Lei 251, de 20 de julho de 1947. Natal: 1947.

${ }^{4}$ Segundo matéria publicada em 2012, o metro quadrado dos terrenos localizados em Tirol e Petrópolis não valeria menos do que 1.500 reais, ver: ECONOMIA, Diário de Natal, Natal, 11 abr. 2012. Outras matérias também ressaltaram essa especulação imobiliária existente nos dois bairros que, no início do século XX, compunham a Cidade Nova: LISBOA, Renato. Dois bairros de charme e conforto. Disponível em: $<\mathrm{http}: / /$ www.asbea.org.br/asbea/assuntos/le_na_midia.asp?cid= 8806>. Acesso em: 24 jun. 2013; HOLLĀNDA, Marcelo. Mercado imobiliário busca preços mais competitivos no RN.
} 
Cidade Nova foi o primeiro bairro planejado de Natal, suas ruas esquadrinhadas e espaçosas, seus enormes quarteirões e suas habitações ecléticas inauguraram uma nova forma de ocupar a cidade, anunciando que Natal não mais seria formada por bairros com características consideradas no período como provincianas. Alguns pesquisadores destacaram que o Plano de Cidade Nova teria estabelecido um padrão espacial para a cidade, definindo, desde 1901, a forma predominante de estruturação urbana de Natal, sendo o único plano que foi implantado em sua totalidade.

Segundo Lima, o processo de urbanização de Natal ao longo do século XX confirmou a predominância desse plano na estruturação da cidade. Todos os planos elaborados nesse período, desde os planos de urbanismo de 1929 e 1935 até os planos diretores de 1968, 1974, 1984 e 1994 obedeceram e regulamentaram as tendências de configuração espacial decorrentes do processo de urbanização condicionado pelo plano de Cidade Nova $^{5}$. Assim, observa-se a necessidade de entender o projeto de intervenção urbana que culminou com a construção do bairro Cidade Nova, uma vez que esse projeto e a ocupação do bairro condicionaram a forma de organização espacial da cidade durante quase um século. Entender o processo de construção e de ocupação desse bairro é também compreender o processo de modernização de Natal e o surgimento de preocupações antes inexistentes, como a ideia de sistematizar e organizar o crescimento e a ocupação da cidade.

Diante da importância do processo de idealização e concretização do bairro Cidade Nova para a história da capital norte-rio-grandense do início do século $X X$, objetiva-se neste texto analisar os trabalhos produzidos sobre aspectos urbanos da

Disponível em: <http://jornaldehoje.com.br/mercado-imobiliariobusca-precos-mais-competitivos/>. Acesso em: 24 jun. 2013; entre outras.

\footnotetext{
${ }^{5}$ Ao ser implantado e expandido, o Plano da Cidade Nova impulsionou o crescimento da cidade na parte situada à margem direita do Rio Potengi, condicionando a expansão da cidade no sentido sul, orientada pelas ruas $e$ avenidas desenhadas por tal plano. Ver: LIMA, Pedro de. Natal século $X X$ : do urbanismo ao planejamento urbano. Natal (RN): EDUFRN, 2001, p.33; p.163.
}

capital norte-rio-grandense, buscando investigar principalmente como essas produções mencionaram o processo de construção e de ocupação do terceiro bairro de Natal. Para tanto, no primeiro tópico, intitulado O urbano tornou-se a torre de Babel das ciências da sociedade, pretende-se discorrer sobre como a história urbana tornou-se objeto de estudo de pesquisadores da História e de áreas afins. Tal análise é de fundamental importância para introduzir a investigação dos trabalhos locais produzidos sobre Cidade Nova, uma vez que a análise proposta por este artigo enquadra-se dentro das preocupações de um trabalho da história social do urbano e não se limita a analisar apenas produções historiográficas.

No tópico Diversos olhares sobre Cidade Nova: historiografia e produção local pretende-se fazer um balanço das produções do campo histórico e de áreas afins sobre a história da cidade de Natal, enfatizando as análises sobre o processo de construção e ocupação de Cidade Nova, ressaltando as contribuições e os elementos que foram desprezados ou minimizados por cada um dos trabalhos discutidos.

Muitos trabalhos produzidos sobre Cidade Nova ressaltam 0 aspecto de novidade que caracterizou o seu processo de idealização e de construção, não mencionando os conflitos políticos e sociais que permearam o processo de concretização e ocupação do novo território urbano criado em 1901, e o processo de apropriação das terras. Ao longo deste artigo pretende-se analisar essas produções e demonstrar como o terceiro bairro de Natal não representou apenas novidade, transformação. Regras foram descumpridas, populares continuaram dividindo a paisagem urbana com membros ligados ao poder local. A ocupação do novo bairro é capaz de demonstrar um exemplo significativo do processo de modernização da Natal do início do século XX, guiado por um grupo mais abastado e influente e caracterizado por mudanças sociais limitadas.

\section{O urbano tornou-se a torre de Babel das ciências da sociedade ${ }^{6}$}

\footnotetext{
${ }^{6}$ Título inspirado na frase de Marcel Roncayolo em: RONCAYOLO, Marcel. Lesgrammaires d'une ville.
} 
Antes de realizar uma revisão historiográfica dos trabalhos produzidos sobre aspectos urbanos da cidade de Natal e que, sobretudo, enfatizaram algum elemento da história do terceiro bairro da cidade, o bairro Cidade Nova, é necessário tecer um breve comentário sobre a história da área em que essa pesquisa está inserida: a história urbana.

A história urbana foi objeto de estudo de diversos campos disciplinares, sendo analisada inicialmente por arquitetos e urbanistas que durante um longo período associaram-na ao âmbito da história da arte e da arquitetura, deixando em segundo plano aspectos sociais, econômicos e políticos. O texto do urbanista Luís Octávio da Silva, História urbana: uma revisão da literatura epistemológica em inglês, é fundamental para entender os marcos e discursões que fizeram parte do campo da história urbana enquanto área de conhecimento, abarcando a segunda metade do século $X X^{7}$. Tendo como base principalmente a literatura britânica e americana, o autor apresentou as referências que marcaram e instituíram a história urbana como campo de conhecimento específico.

Segundo Silva, compartilhando do pensamento de François Bédarida, foi, sobretudo a partir de 1929, com a publicação dos Annalesd'Histoire Economique et Sociale, que os historiadores passaram a intensificar o interesse pelo urbano. Outros campos disciplinares, como a geografia e a demografia, também desenvolveram análises sobre essa temática. Nota-se, pois, que inicialmente os trabalhos referentes ao urbano não formavam um campo comum, perpassavam várias áreas com propostas teóricas heterogêneas ${ }^{8}$.

Apenas na segunda metade do século $X X$ a história urbana passou a ser um campo de

Essaisurlagenènesedesstructuresurbaines à Marseille. Paris: Éditions de l'EHESS, 1996. p.20. O título anuncia o caráter interdisciplinar dos estudos urbanos.

${ }^{7}$ SILVA, Luís Octávio da. História urbana: uma revisão da literatura epistemológica em inglês. EURE (Santiago)- Revista latinoamericana de estudios urbano regionales, Santiago, v. XXVIII, n.83, 2002.

${ }^{8}$ Ibidem, p.32. conhecimento específico. A década de 1960 foi um marco para essa consolidação, com 0 desenvolvimento de trabalhos sobre a história do processo de urbanização e de grupos de pesquisas voltados para os estudos urbanos com pesquisadores que passaram a denominarem-se historiadores urbanos, tais como $\mathrm{O}$ Grupo de História Urbana, formado na Universidade de Leicester (Inglaterra), em 1963, por H. J. Dyos, que passou a publicar periodicamente um boletim com bibliografia referente à temática, contribuindo para difundir a história urbana cada vez mais.

Silva comentou que 0 artigo de Dyos intitulado Agenda for Urban Historians propôs duas abordagens possíveis para a temática urbana: a particularista, que seria identificada com os estudos de casos específicos, ligados à história de cidades, e uma abordagem generalista, voltada para processos mais gerais, organizados em volta de temas como o processo de urbanização, o desenvolvimento econômico, o tecnológico, etc. Entre os historiadores também surgiram duas maneiras de entender o urbano. Alguns, que partilhavam a ideia de cidade enquanto processo, entendiam que o urbano aplicava-se a uma determinada dimensão da história que não poderia ser explicada por outros quadros de referência, como a história econômica ou a história cultural. Outros compreendiam o urbano apenas como local em que se desenrolavam embates e transformações sociais, tal visão ficou conhecida como perspectiva do urbano enquanto sítio ${ }^{9}$.

Nos Estados Unidos deve-se destacar a atuação New Urban History, que foi inaugurada na Conferência Nineteenth Century Industrial City, organizada na Universidade de Yale, EUA, em 1968. Esse grupo apresentou uma perspectiva sociológica identificada com a abordagem do urbano enquanto sítio, diferentemente do grupo Leicester que enfatizava aspectos ligados à

\footnotetext{
${ }^{9}$ Sobre essa discussão ver ainda MONTEIRO, Charles. Entre história urbana e história da cidade: questões e debates. Oficina do Historiador, Porto Alegre, v.5, n.1, jan/jun. 2012. p.101-112.
} 
história econômica e identificava-se com a abordagem da cidade como processo. A New UrbanHistory já em meados da década de 1970 foi alvo de críticas severas, apesar de ter contribuído na operacionalização da transferência de procedimentos metodológicos da sociologia para o âmbito urbano, a concepção limitada do urbano nessa corrente fez com que fosse duramente criticada.

Grupos como o de Leicester e eventos como Nineteenth ajudaram a estabelecer referências teóricas comuns, procedimentos metodológicos, publicações, associações, entre outras iniciativas que contribuíram para consolidar um verdadeiro campo da história urbana. Na década de 1980, ressaltou Silva, os balanços sobre as produções de história urbana destacaram a necessidade de aprofundar a discussão sobre a transdicisplinaridade e estudos comparativos. Foi também durante essa década que a abordagem quantitativa norte-americana foi bastante criticada e sugiram várias produções francesas e alemãs ${ }^{10}$. $\mathrm{Na}$ década de 1990 a história urbana passou por um período de maior dinamismo e disseminação, contando com trabalhos comparativos, que iam além da dimensão local. O texto de Silva torna-se importante por ser um dos primeiros a elaborar um histórico do desenvolvimento da história urbana ocidental.

No Brasil, foi a partir das décadas de 1980 e 1990 que o número de pesquisas sobre a construção da história das cidades brasileiras tornou-se expressivo. Foi nesse período também que começaram a ser criados seminários de discussão sobre a história da cidade e planejamento urbano. A abordagem interdisciplinar esteve presente nessas pesquisas, elaboradas por arquitetos, planejadores, geógrafos, historiadores, entre outros profissionais vinculados à temática urbana.

\footnotetext{
${ }^{10}$ Para uma comparação entre essas diferentes tradições de história urbana ver: PINO, Jean-Luc. Le monde desvillesau XIX siècle. Paris: Hachette, 1991.
}

O texto de Vidal, Tendances recentes de larecherchesurl' histoiredu Brésilurbain, é referência para entender o caminho das pesquisas em história urbana no Brasil ${ }^{11}$. O autor iniciou o artigo revendo 0 posicionamento sobre a organização da cidade colonial, que foi consolidado por Sérgio Buarque de Holanda em Raízes do Brasil. Holanda apresentou a cidade colonial como um mal necessário para o desenvolvimento da empresa rural, enfatizando que em seu processo de colonização os portugueses, diferentemente dos espanhóis, foram negligentes e não organizaram suas cidades como deveriam. Vidal estabeleceu uma contraposição a essa ideia, ressaltando que já na década de 1960 e 1970 geógrafos e planejadores começaram a reavaliar o papel da cidade na política colonial portuguesa e o papel das sociedades urbanas no mundo colonial. ${ }^{12}$ Entretanto, só a partir de meados da década de 1980 que o interesse pela história do Brasil urbano foi despertado.

O texto de Vidal ainda apresentou um balanço dos trabalhos produzidos entre 1990 e 2003 no que se refere à história do Brasil urbano. Nesse período foram produzidos 237 trabalhos, dos quais 56\% foram publicados no Brasil, 15\% nos Estados Unidos, 15\% na França e 10\% em Portugal. O autor demonstrou que a maior parte dos estudos realizados no Brasil dedicou-se a pesquisas sobre a cidade no período de 1880 1930. O texto de Vidal é referência importante para

\footnotetext{
${ }^{11}$ VIDAL, Laurent. Tendances recentes de larecherchesurl' histoiredu Brésilurbain. Élémentspourunbilan: 1990-2003. Histoireurbaine, n.12, 2005, p.161-163.

${ }^{12}$ Vidal organizou uma coletânea de textos em 2008 que, entre outros objetivos, também questionou a ideia lançada por Sérgio Buarque de Holanda a respeito da falta de planejamento das cidades brasileiras criadas pela metrópole portuguesa. Para aprofundar o tema ver: Laurent Vidal (Org.). La villeauBrésil $\left(X V I I I^{e}-X X^{e}\right.$ siècles):naissances, renaissances. Paris: Rivagesdes Xantons, 2008. A historiadora Maria Fernanda Bicalho também elaborou uma ótima contraposição ao texto de Holanda, demonstrando, por meio do cruzamento de variadas fontes, como os portugueses desenvolveram todo um processo de burocracia e instituições voltadas para a organização das cidades coloniais, destacando, pois, que pensar o ordenamento da cidade não é um problema apenas do período republicano. Para o aprofundamento dessas ideias, ver capítulos 6, 7 e 8 do livro BICALHO, Maria Fernanda. A cidade e o império: o Rio de Janeiro no século XVIII. Rio de Janeiro: Civilização Brasileira, 2003.
} 
os pesquisadores da temática urbana, que podem entrar em contato, ao final do texto, com uma vasta e diversificada bibliografia sobre estudos da cidade em seus mais variados aspectos e recortes temporais $^{13}$.

Uma referência importante para os estudos de história urbana no Brasil são os anais e demais publicações da Associação Nacional de PósGraduação e Pesquisa em Planejamento Urbano e Regional (ANPUR), formada por programas universitários de pós-graduação e entidades brasileiras que desenvolvem atividades de ensino e de pesquisa nesse campo de estudo. A ANPUR realiza, desde o ano de 1986, encontros nacionais a cada dois anos para debater trabalhos sobre estudos urbanos e regionais, sendo um local importante para a discussão de pesquisas e caminhos relacionados à história da cidade.

Segundo Eloísa Pinheiro e Ivone Salgado, membros da ANPUR, a vasta produção que se observou nos Encontros Nacionais da ANPUR e nos Seminários de História da Cidade e do Urbanismo foi produzida principalmente por arquitetos e urbanistas, bem como por geógrafos e sociólogos, sendo um reflexo do crescimento da Pós-Graduação na área de Arquitetura e Urbanismo como também na área de Planejamento Urbano e Regional ${ }^{14}$. Para as autoras, as preocupações e questões levantadas a partir da década de 1980 tem sido múltiplas. Se, inicialmente, os estudos eram concentrados no urbanismo sanitarista do século XX, com o passar do tempo os pesquisadores começaram a estudar questões relacionadas à forma, à estética, à legislação e à gestão das cidades. Os estudos sobre as cidades ampliaram o recorte temporal,

\footnotetext{
${ }^{13}$ Ver VIDAL, Laurent. Tendances recentes de larecherchesurl' histoiredu Brésilurbain. Éléments pourunbilan: 1990-2003. Op. cit., p.161-163.

${ }^{14}$ As autoras teceram esse comentário no simpósio História, cidade e urbanismo, durante o Encontro Nacional da Anpur ocorrido em maio de 2007, ver: ENCONTRO NACIONAL DA ANPUR, 2007, Belém. Anais eletrônicos do XII Encontro Nacional da Anpur. Disponívrl em <http://www.anpur.org.br/inicio/index.php/2012-09-13-13-0843/anais>. Acesso em: 23 dez. 2012.
}

incluindo o período colonial e avançando até a contemporaneidade, estendendo também os limites espaciais, ultrapassando o âmbito das cidades capitais e das regiões sudeste e nordeste.

Os trabalhos de Bernard Lepetit também são referência para pensar os caminhos da história urbana a partir da década de 1990. A obra Por uma nova história urbana, organizada por Heliana Angotti Salgueiro e formada pela tradução de artigos produzidos, em sua maioria, na década de 1990, por Lepetit, é uma excelente contribuição para os autores que se dedicam à pesquisa urbana $^{15}$. Nesses artigos Lepetit ressaltou a relação indissociável existente entre os grupos sociais e a configuração material da cidade, compreendendo-a como espacialidade material e simbólica, envolvida por diferentes significações e temporalidades.

Uma das principais contribuições de Lepetit foi a forma de compreender a importância da interdisciplinaridade $^{16}$. Para esse autor, a cidade não é somente um cenário ou uma moldura, mas um ponto de convergência de enfoques pluridisciplinares. Segundo Lepetit, uma disciplina nunca se expõe passivamente às influências externas, por isso a interdisciplinaridade seria um caso particular de transferência cultural. Toda transferência de conceitos, problemas ou métodos seria acompanhada da transformação destes, do processo de tradução. Assim, o autor entende que as contribuições das diferentes áreas de conhecimento são traduzidas nos trabalhos de história urbana e podem ser responsáveis até mesmo pelo surgimento de novos objetos de estudo e de condições para produzir novos saberes.

Segundo Lepetit, até o final da década de 1960 a cidade não era, na França,

\footnotetext{
${ }^{15}$ LEPETIT, Bernard. Por uma nova história urbana. Organização: HelianaAngotti Salgueiro. São Paulo: Edusp, 2001 ${ }^{16}$ Para melhor aprofundamento da noção de interdisciplinaridade de Lepetit, ver: LEPETIT, Bernard. Proposições para uma prática restrita da interdisciplinaridade. In: . Por uma nova história urbana. Op. cit.
} 
verdadeiramente um objeto de pesquisa histórica. A sua emergência como objeto histórico resultou mais da confrontação cruzada das interrogações das ciências humanas do que do desenvolvimento da historiografia. Dessa maneira, nota-se como a prática da interdisciplinaridade foi fundamental para a própria emergência da preocupação histórica com a cidade.

Ainda sobre a história da pesquisa urbana no Brasil, deve-se ressaltar a importância dos estudos de Maria Stella Brescianni, sobretudo o intitulado História e Historiografia das cidades, um percurso $^{17}$. Nesse texto a autora mapeou uma pequena parte da extensa produção acadêmica sobre questões relativas às cidades, destacando, assim como Vidal e os membros da ANPUR, que somente na década de 1980 os estudos sobre as cidades ganharam definição precisa como linha de pesquisa em programas de pós-graduação nas universidades brasileiras, permitindo a formação de grupos de pesquisadores e estimulando os estudos urbanos no campo da própria historiografia.

A autora citou, entre outros trabalhos considerados cruciais para o estudo das cidades, 0 artigo de François Beguin, publicado no número 29 da revista Recherche, como sendo um marco importante, pois com ele foi possível acompanhar a problematização das cidades por meio da elaboração de uma denominada questão urbana. Beguin destacou no seu artigo o começo do que viria a ser o urbanismo moderno, em seu encontro com o saber médico e com as técnicas da engenharia, sendo responsável por configurar as bases das práticas sanitárias que se mantiveram até o início do século XX. Brescianni também comentou a importância dos trabalhos de Walter Benjamin e Georg Simmel. Com Benjamim e

\footnotetext{
${ }^{17}$ BRESCIANI, Maria Stella. História e Historiografia das cidades, um percurso. In: FREITAS, Marcos Cézar de (org.). Historiografia brasileira em perspectiva. São Paulo: Contexto, 2010.
}

Simmel a autora destacou ter aprendido a ter percepção da sensibilidade para as coisas urbanas. Para tal autora, Simmel e Benjamin leram a cidade dentro do seu próprio tempo e ritmo, dentro da velocidade acelerada e da simultaneidade. Compreenderam a cidade não somente como oposição à tranquilidade da vida do campo, mas sim em sua lógica própria, observando a voracidade, a criatividade.

Todos os textos comentados são importantes para o entendimento de como a história urbana consolidou-se enquanto área de conhecimento específico. Em função da limitação de páginas e pretensões deste artigo, optou-se pela seleção dos textos considerados mais pertinentes para traçar um histórico da história das cidades. Entretanto, deve-se ressaltar que existem vários outros textos, livros e autores que podem ser utilizados como fontes para o entendimento dos percursos da história urbana internacional e do Brasil $^{18}$.

No próximo tópico deste artigo será elaborada uma análise das produções locais referentes à cidade de Natal, sobretudo aquelas que mencionam o processo de construção do terceiro bairro da cidade, Cidade Nova. Para essa análise não serão investigadas apenas obras do campo da História. Conforme foi discutido neste primeiro tópico temático, a história urbana não foi uma preocupação exclusiva do campo histórico, tendo sido objeto de estudo de arquitetos e urbanistas, planejadores urbanos e regionais, geográficos, e pesquisadores vinculados a outras áreas.

\footnotetext{
${ }^{18}$ Entre esses ver: SCHORSKE, Carl. A ideia de cidade no pensamento europeu: de Voltaire a Spengler. In: Pensando com a história. São Paulo: Companhia das Letras, 2000; PECHMAN, Robert; RIBEIRO, Luís César de Queiroz (orgs.). Cidade, povo e nação: gênese do urbanismo moderno. Rio de Janeiro: Civilização Brasileira, 1996; SALGUEIRO, HelianaAngotti (Org.). Cidades capitais do século XIX: racionalidade, cosmopolitismo e transferência de modelos. São Paulo: Editora da Universidade de São Paulo, 2001; entre outros.
} 


\section{Diversos olhares sobre Cidade Nova: historiografia e produção local}

Pesquisas sobre o processo de urbanização de Natal começaram a ser desenvolvidas principalmente na década de 1980, a partir de um processo de qualificação do quadro de professores da Universidade Federal do Rio Grande do Norte, seguindo percurso semelhante ao das pesquisas sobre história da cidade no resto do país. Entretanto, antes de examinar a produção local iniciada na década de 1980, faz-se necessário comentar a primeira obra que sistematizou a história da capital norte-rio-grandense, o livro História da Cidade do Natal, escrito por aquele que foi nomeado historiador da cidade, Luís da Câmara Cascudo ${ }^{19}$.

Antes dessa publicação de Cascudo sobre Natal não havia nenhum livro que estivesse voltado exclusivamente para o passado da capital norte-riograndense. A obra História da Cidade do Natal foi publicada apenas em 1947, a pedido do então prefeito Sylvio Pedroza e reuniu várias crônicas publicadas por Cascudo na imprensa oficial entre 1930 e 1940. Escrito no contexto do pós-guerra, em que a cidade passava por várias mudanças em seus equipamentos urbanos, o livro tencionou reunir aspectos do passado da capital, recordando lugares e nomes que deixaram de existir em meio a esse processo de mudanças ${ }^{20}$.

Trata-se de um livro que abordou aspectos de três séculos e meio da história da cidade, sendo muito mais que um mero compêndio de informações sobre Natal. Nessa obra, Cascudo deixou transparecer a ambivalência que Ihe rondava, entre o encantamento pelas reformas de modernização vivenciadas na cidade e um apego à tradição, a um sentimento de nostalgia pelo passado que estava sendo modificado por meio de reformas urbanas ${ }^{21}$.

\footnotetext{
${ }^{19}$ CASCUDO, Luís da Câmara. História da Cidade do Natal. Natal: Editora da UFRN, 2010.

${ }^{20}$ ARRAIS, Raimundo. Do alto da torre da matriz, acompanhando a procissão dos mortos: Luís da Câmara Cascudo, o historiador da cidade do Natal. Espacialidades, Natal,v. 2, n. 1. 2009.

${ }^{21}$ Esses pensamentos e sentimentos ambivalentes são característicos da maior parte dos cronistas, dos poetas e dos intelectuais que escreveram sobre a cidade em processo de
}

Como destacou o historiador Raimundo Arrais, apesar de expressar em seu livro uma história tradicional, baseada em datas, em marcos políticos e em heróis fundadores, Cascudo também se dedicou ao que Arrais denominou de "refugos da modernização", ou seja, procurou estudar os elementos de sobrevivência da cidade antiga, nos quais pretendia encontrar os vestígios da cultura popular $^{22}$.

Logo na introdução de sua obra, Cascudo destacou como iria abordar a história da cidade, compreendendo-a enquanto um organismo vivo, como um sujeito que nasce, cresce e caminha para a sua fase final. Dessa maneira, no livro foram abordados desde a fundação da cidade, no período colonial, até os últimos feitos da década de 1940, quando a obra foi publicada. Os assuntos foram organizados por meio de uma ordem cronológica, dando-se mais importância aos temas em que o autor encontrou maior número de documentação. Trata-se de uma história que se pretendia totalizante, que refletia a tradição intelectual com a qual o autor afinava-se. A escolha dos temas de Cascudo foi baseada, por exemplo, na forma como os viajantes do século XIX organizavam as descrições das cidades pelas quais passavam ${ }^{23}$.

Em relação à Cidade Nova, na obra História da Cidade do Natal Cascudo apenas comentou o momento de construção do bairro, citando Pedro Velho ${ }^{24}$ como idealizador desse que seria o terceiro

modernização, como Baudelaire escrevendo sobre a modernização de Paris; João do Rio construindo imagens da modernização carioca e o próprio Henrique Castriciano escrevendo sobre a implantação da modernização na Natal do início do século XX. Ver: SIQUEIRA, Gabriela Fernandes de. O homem que pintava a cidade por meio de palavras: cenas urbanas natalenses construídas a partir das crônicas de Henrique Castriciano. Cordis - Revista Eletrônica de História Social da Cidade, São Paulo, n.10, p. 93-131, jan/jun. 2013.

${ }^{22}$ ARRAIS, Raimundo. Do alto da torre da matriz, acompanhando a procissão dos mortos. Op. cit., p.8.

${ }^{23}$ Para uma análise mais profunda sobre os autores e concepções que influenciaram a escrita cascudiana, ver: ARRAIS, Raimundo. Posfácio. In: CASCUDO, Luís da Câmara. História da Cidade do Natal. Op. cit.

${ }^{24}$ Pedro Velho de Albuquerque Maranhão foi uma das principais lideranças da família Albuquerque Maranhão. Essa família foi responsável por dominar o poder local ao longo das primeiras décadas do século XX. Pedro Velho era filho do pernambucano Amaro Barreto de Albuquerque Maranhão e Feliciana Maria da Silva Pedroza. O casamento de Amaro Barreto e Feliciana Pedroza culminou com a formação de uma extensa família, com quatorze filhos, dentre os quais dois assumiram o governo do 
bairro oficial da cidade. Apesar de resumida, a narrativa cascudiana sobre Cidade Nova demonstrou seguir as mesmas linhas da narrativa estadual elaborada no início do século XX: ressaltou-se o herói dos Albuquerque Maranhão e a importância dos grupos dirigentes na concretização, embora lenta, do bairro idealizado.

Cascudo elucidou que Pedro Velho, quando foi governador do estado (1892-1896), já tinha a intenção de construir um bairro planejado naquela região de matas por onde realizava seus passeios a cavalo, mas, por falta de recursos, a obra não foi realizada. Assim, de acordo com a narrativa cascudiana, somente na gestão seguinte, de Alberto Maranhão, o projeto do terceiro bairro da cidade foi colocado em prática. Observa-se que, mesmo executado na gestão de seu irmão, o projeto era creditado a Pedro Velho, legitimando a construção histórica iniciada no início do século XX a respeito da "heroicidade pedrovelhista". Essa informação sobre a idealização do bairro ter partido de Pedro Velho foi reproduzida em quase todas as obras e textos que se referem à Cidade Nova.

Cascudo ainda apresentou em seu texto a transcrição de uma carta de Alberto Maranhão ${ }^{25}$ que

estado, Pedro Velho e Alberto Maranhão. Em Natal, além de clinicar em cardiologia, ginecologia e obstetrícia, Pedro Velho era também professor de História do Atheneu Norte-riograndense. Foi um dos fundadores, em 1889, do Partido Republicano do Rio Grande do Norte e, nesse mesmo ano, para divulgar o ideário republicano, fundou o jornal $A$ Republica. Após a proclamação da República, em 17 de novembro de 1889, Pedro Velho foi aclamado presidente do governo provisório do Rio Grande do Norte, permanecendo no cargo até dezembro de 1889, quando o governo federal nomeou Adolfo Gordo para substituí-lo. Em 1892 Pedro Velho retornou ao cargo de governador permanecendo até 1896, uma vez que venceu as eleições indiretas. Esse período em que Pedro Velho atuou como governador, diferentemente do que alguns autores locais afirmam, não foi capaz de consolidar o grupo Albuquerque Maranhão. Foi um período crítico, de luta pelo controle do aparelho regional, com confrontos diretos. Para Almir Bueno, somente em 1895, com a vitória de Ferreira Chaves nas eleições para governador do estado, que contou com forte apoio de Pedro Velho, o poder da família Albuquerque Maranhão foi consolidado. Pedro Velho foi ainda deputado federal durante duas gestões (1891-1892/ 1896) e senador entre 1896 e 1907. Ver: CARDOSO, Rejane (coord.). 400 nomes de Natal. Natal: Prefeitura de Natal, 2000, p.53; CASCUDO, Luís da Câmara. Vida de Pedro Velho. Natal: Editora da UFRN, 2008; BUENO, Almir de Carvalho. Visões de República: idéias e práticas políticas no Rio Grande do Norte (1880-1895). Tese (Doutorado em História). Programa de PósGraduação em História, Universidade Federal de Pernambuco (UFPE), Recife, 1999.

${ }^{25}$ Alberto Frederico de Albuquerque Maranhão (1872-1944) formou-se em Direito pela Faculdade de Direito de Recife em 1892 e já nesse ano foi nomeado promotor público de Macaíba. explicava a origem dos nomes de várias propriedades existentes na região, sempre associados a nomes de regiões europeias ou títulos da literatura. Todos os proprietários citados por Maranhão eram membros partícipes dos grupos mais abastados existentes na cidade no período, referidos por Maranhão como desbravadores, "bandeirantes de Petrópolis e Tirol"26. A ideia dos heróis fundadores era evidente na narrativa cascudiana da década de 1940.

Nota-se que Cascudo não realizou um trabalho histórico mais aprofundado sobre o bairro, pois este não era seu objetivo. Cascudo estava elaborando, de forma encomendada, a primeira história da cidade, em uma perspectiva totalizante. Ele não tinha, pois, a pretensão de escrever detalhadamente a história de um de seus bairros. Como já explicitado, pesquisas sobre 0 desenvolvimento urbano da cidade começaram a ser desenvolvidas na década de 1980, o que fez e faz do trabalho de Câmara Cascudo, mesmo com suas limitações, uma referência inicial para estudos sobre aspectos urbanos da cidade.

Em relação à produção local iniciada de forma mais significativa na década de 1980, deve-se destacar a produção do grupo de pesquisa História da Cidade e do Urbanismo (HCURB), vinculado ao Departamento de Arquitetura e Urbanismo da Universidade Federal do Rio Grande do Norte, e dos pesquisadores associados a tal grupo. Surgido em meados de 1998, esse grupo começou a desenvolver pesquisas sobre intervenções planejadas e

Entre 1892 e 1896 também atuou como Secretário do Governo na administração de seu irmão Pedro Velho. No ano de 1895 firmou matrimônio com sua sobrinha, Inês Barreto de Albuquerque Maranhão, filha do importante industrial Juvino Cezar Paes Barreto e Inês Augusta de Albuquerque Maranhão Paes Barreto, irmã de Alberto. Alberto Maranhão foi também redator do A Republica até o ano de 1900. Entre 1900 e 1904 exerceu o cargo de governador do Rio Grande do Norte. Provavelmente o casamento de Maranhão com sua sobrinha tenha ocorrido para fortalecer os laços familiares e manter integrada a família Albuquerque Maranhão. Após o primeiro mandato como governador, Alberto Maranhão exerceu o cargo de deputado federal, até ser novamente eleito para o cargo de governador, exercendo seu mandato entre 1908 e 1913. Após o término de seu segundo mandato, foi eleito deputado federal pelo Rio Grande do Norte em 1915, sendo continuamente reeleito até 1929. Ver: PEIXOTO, Renato Amado. Verbete Alberto Maranhão. In: ABREU, Alzira de (org.). Dicionário histórico-biográfico da Primeira República. Rio de Janeiro: Editora da Fundação Getúlio Vargas, 2012. Disponível em: $<$ http://cpdoc.fgv.br/dicionario-primeira-republica>. Acesso em: 26 maio 2015.

${ }^{26}$ CASCUDO, Luís da Câmara. Op. cit., p.438. 
implicações de inovações técnicas na transformação do espaço urbano natalense. O grupo realizou um trabalho pioneiro, iniciando pesquisa nos arquivos da cidade, tentando problematizar os planos urbanísticos, localizando-os no contexto social, cultural e técnico de Natal, além de formar uma ampla base de dados físicos e digitais que foram e são utilizados como fontes em vários artigos, monografias, dissertações e teses de pesquisadores de vários departamentos da UFRN e de outras universidades.

Devido a esse intenso e pioneiro trabalho de pesquisa em arquivos, análise de fontes e reflexão de temas e abordagens, o estudo de alguns objetos, como o processo de construção e de ocupação do bairro Cidade Nova, por exemplo, não foi muito aprofundado. Assim, uma das principais publicações do grupo em parceria com professores de outros departamentos da UFRN, realizada em 2006, o livro Surge et Ambula, fez pouca referência ao bairro Cidade Nova $^{27}$. Trata-se de uma obra que pretendeu divulgar para um público mais amplo a produção do HCURB com novas contribuições e novas fontes para discutir a história urbana da cidade do Natal entre 1890 e 1940.

Apesar das poucas referências ao bairro Cidade Nova, essa publicação apresentou uma perspectiva diferente da existente na obra de Câmara Cascudo. Os pesquisadores que participaram da escrita do livro, diferentemente de Cascudo, não analisaram a construção do bairro Cidade Nova e de outras reformas ocorridas no início do século $X X$ apenas como a materialização das reformas urbanas, como simples empréstimos dos modelos europeus ou como meras reformas no espaço físico da cidade realizadas pela administração de Pedro Velho e dos de sua estirpe.

Embora a maior parte dos textos faça referência a essa reforma material, cruzando-a com os investimentos do poder político, os pesquisadores chamaram atenção para o aspecto da representação, entenderam que essas reformas também podem ser

\footnotetext{
${ }^{27}$ FERREIRA, Angela Lucia et.al. Surge et Ambula: a construção de uma cidade moderna (Natal, 1890-1940). Natal: Editora da UFRN, 2006.
}

compreendidas na perspectiva simbólica, como mecanismos de representação desse poder local que queria fazer-se presente na nova realidade republicana, esforçando-se, pois, para mudar a imagem da cidade $^{28}$. Nesse sentido, os pesquisadores buscaram estudar os vários discursos literários e técnicos surgidos nesse período de transformações urbanas, analisando as transferências, traduções e ressonâncias das ideias e modelos urbanísticos europeus e norte-americanos nos planos elaborados para Natal na primeira metade do século XX. De forma geral, trata-se de um trabalho que privilegiou assuntos gerais e um recorte temporal amplo, o que muitas vezes prejudicou a análise específica de determinadas temáticas.

$\mathrm{O}$ arquiteto Pedro de Lima, também vinculado ao Departamento de Arquitetura e Urbanismo da UFRN, publicou, em 2001, um livro, fruto de sua tese de doutorado, referência para o estudo da história urbana da cidade, intitulado Natal século $X X$ : do urbanismo ao planejamento urbano ${ }^{29}$. Nessa obra, o autor estudou os aspectos urbanos da cidade de Natal, abordando desde as transformações urbanas e planos urbanísticos do início do século $X X$ até a análise dos planos diretores elaborados para a cidade na década de 1990.

No primeiro capítulo de sua obra, República: novo regime, Cidade Nova, Lima discorreu sobre o bairro Cidade Nova, ressaltando-o como espaço que servia aos interesses dos grupos que emergiam com a instauração da República. Lima foi ainda o primeiro autor que apontou a importância do Plano de Cidade Nova, elucidando que foi o único plano urbanístico, até a década de 1990, totalmente implantado e responsável por estabelecer um padrão espacial para a cidade, fazendo com que a ocupação de Natal fosse estruturada na margem direita do rio Potengi.

Em muitas passagens desse capítulo o autor citou trechos do livro História da Cidade do Natal, reafirmando o papel essencial da figura de Pedro Velho de Albuquerque Maranhão na idealização de Cidade Nova, bem como enfatizando a importância

\footnotetext{
${ }^{28}$ Ibidem, p.107-119.

${ }^{29}$ LIMA, Pedro de. Natal século $X X$ : do urbanismo ao planejamento urbano. Natal: EDUFRN, 2001.
} 
de sua organização familiar na implantação das reformas de modernização na cidade. O autor abordou a construção de Cidade Nova como um elemento importante para consolidar a expansão física da cidade, também a tratando como sendo importante para representar o governo republicano que tinha instalando-se no início do século XX. Todavia, o autor não analisou com profundidade a relação entre idealização e prática dessas reformas.

Pedro de Lima também destacou que o processo de ocupação do bairro Cidade Nova ocorreu de forma lenta, acentuando-se, sobretudo, após a Segunda Guerra Mundial. Entretanto, o autor não destacou os motivos dessa ocupação lenta, não se preocupando em discutir as formas de uso e de apropriação do solo urbano no bairro, uma vez que esse não era o objetivo de sua obra. Em algumas passagens o autor até citou que os lotes de terras do bairro foram distribuídos entre as famílias ilustres da cidade, mas não problematizou como essa distribuição ocorreu. Lima apresentou ainda a existência de um mercado de terras em Natal e, sobretudo, em Cidade Nova, no início do século XX. Entretanto, o autor apenas citou essa informação no texto, não destacando como esse mercado foi configurado. Logo em seguida, Lima enfatizou que esse mercado de terras seria efetivado plenamente somente na década de 1940, no contexto da Segunda Guerra Mundial, quando teria ocorrido maior desenvolvimento e ocupação da área de Cidade Nova. O trabalho de Lima foi importante por mapear diferentes aspectos e agentes sociais que interferiram no processo de urbanização do Rio Grande do Norte e de sua capital ao longo de um século ${ }^{30}$.

Vale ressaltar, conforme discutido na dissertação Por uma "Cidade Nova": apropriação e

\footnotetext{
${ }^{30}$ Lima também elaborou outros trabalhos que fizeram referência a aspectos urbanos da cidade. Entretanto, a maior parte desses trabalhos foi originada das reflexões elaboradas no livro Natal século $X X$ : do urbanismo ao planejamento urbano, fruto de sua tese de doutorado defendida em 1998, junto ao Programa de Pós-Graduação em Estruturas Ambientais e Urbanas da Faculdade de Arquitetura e Urbanismo da Universidade de São Paulo. Entre essas outras obras destacam-se: LIMA, Pedro de. O mito da fundação de Natal e a construção da cidade moderna segundo Manoel Dantas. Natal: Sebo Vermelho, 2000; LIMA, Pedro de. Luís da Câmara Cascudo e a questão urbana em Natal. Natal: Editora da UFRN, 2006; LIMA, Pedro de. Cidade sempre nova e outros escritos. Natal: Plena, 2008.
}

uso do solo urbano no terceiro bairro de Natal, de autoria de Gabriela Siqueira ${ }^{31}$, que esse mercado de terras existente em Natal no início do século XX não era configurado por meio da venda da propriedade no sentido moderno ${ }^{32}$, mas sim da venda do domínio útil, da venda do direito de aforar, já que o domínio direto daquelas terras em Cidade Nova continuaria sendo da Intendência Municipal.

O foreiro, indivíduo que aforava o terreno, tinha direito de construir e alienar a terra ou alguma propriedade construída, mas o novo foreiro continuaria pagando o aforamento e o laudêmio ${ }^{33}$ ao poder municipal, que era o senhorio, que possuía o domínio direto das terras ${ }^{34}$. Os registros cartoriais pesquisados no $3^{\circ}$ Ofício de Notas, cartório instalado em Natal em 1902, já demonstraram a existência de um mercado de terras em Natal muito antes da década de 1940.

\footnotetext{
${ }^{31}$ SIQUEIRA, Gabriela Fernandes de. Por uma "Cidade Nova": apropriação e uso do solo urbano no terceiro bairro de Natal (1901-1929). Op. cit.

${ }^{32}$ Para Congost, a propriedade é o resultado de múltiplas facetas da atividade humana, não sendo apenas fruto das decisões dos legisladores. A autora defende que não existe apenas o modelo de propriedade que foi imposto pelos códigos dos séculos XIX e XX, a propriedade moderna, perfeita e absoluta. A propriedade deve ser compreendida como um produto das relações sociais existentes, e, aceitar a definição de determinado direito de propriedade como única é assumir uma visão simples e linear da história. Essa linha de análise também é seguida por Paolo Grossi. Segundo o autor, não se pode considerar como única aquela que é simplesmente uma solução histórica dominante. Assim, mesmo com a configuração da forma proprietária moderna, marcada pela simplicidade, abstração e pleno vínculo com um indivíduo, valores proprietários baseados na divisão dos domínios também permaneceram, levando consigo suas ambivalências. Dessa maneira, deve-se considerar o aforamento, que requer a divisão dos domínios, como um modelo proprietário. Ver: CONGOST, Rosa. Tierras, leyes, história: estúdios sobre lagran obra de lapropiedad. Barcelona: Crítica, 2007; GROSSI. Paolo. A propriedade e as propriedades na oficina do historiador. In: Historia da propriedade e outros ensaios. Rio de Janeiro: Renovar, 2006. p.16.

${ }^{33} \mathrm{O}$ laudêmio, imposto de transferência, só seria pago se o foreiro alienasse o terreno a outrem.

${ }^{34} \mathrm{O}$ aforamento é estabelecido mediante contrato perpétuo, em que o titular da propriedade confere a outrem os poderes de seu uso, gozo e disposição ${ }^{34}$. Trata-se de uma forma proprietária baseada na concepção de domínios divididos (direto e útil). Nesse modelo existe um sujeito, o senhorio, que possui o domínio direto do terreno, e outro, o foreiro ou enfiteuta, que possui o domínio útil do mesmo, podendo gozar de benefícios como construir, habitar e até mesmo alienar o domínio útil do terreno, devendo cumprir algumas obrigações como o pagamento de uma taxa anual, denominada foro, e taxas de transferência, de expedições de cartas, entre outros emolumentos. Ver: AMORIM, Edgar Carlos de. Teoria e prática da enfiteuse. Rio de Janeiro: Editora Forense, 1986.
} 
A documentação cartorial registrou a movimentação das terras, para quem essas terras eram repassadas e o motivo da alienação (pagamento, venda do direito de aforar, herança, etc). O estudo das cartas de aforamento também anunciou esse mercado de terras. Muitas cartas apresentaram o histórico de suas movimentações, mencionando os foreiros anteriores e, pelo estudo dessas cartas e cruzamento com outras, observa-se que muitos foreiros compravam o direito de aforar de um primeiro foreiro, dividiam a terra em duas partes (processo denominado de desmembramento) e vendiam, portanto, o domínio útil dos terrenos, lucrando por meio dos rendimentos obtidos. Nota-se, pois, que a existência de um mercado de terras em Natal foi anterior ao período da Segunda Guerra.

O trabalho de Siqueira demonstrou como o parcelamento do solo e a sua alienação era uma constante bem antes da década de 1940. A autora ainda apontou a existência de um mercado de terras pessoal, em que a formação do preço da terra não estava baseada exclusivamente no intuito de transacionar capital econômico. A política de apropriação de terra foi utilizada como um mecanismo de fortalecimento dos grupos influentes politicamente. Os intendentes permitiam alienações constantes do patrimônio público, concediam latifúndios cobrando foros simbólicos e não revogavam os aforamentos de enfiteutas que passavam anos sem construir e sem pagar as taxas.

Outra contribuição importante para os estudos de aspectos urbanos da cidade de Natal é o trabalho de Rubenilson Teixeira, Da cidade de Deus à cidade dos homens ${ }^{35}$. O autor, também professor do Departamento de Arquitetura da UFRN, buscou estudar o processo de secularização existente em doze cidades norte-rio-grandenses entre 1700 e 1960, investigando as marcas desse processo nos espaços urbanos dessas cidades, compartilhando a noção de que é o uso que se faz do espaço ao longo do tempo que lhe confere um ou outro sentido.

\footnotetext{
${ }^{35}$ TEIXEIRA, RubenilsonBrazão. Da cidade de Deus à cidade dos homens: a secularização do uso, da forma e da função urbana. Natal: Editora da UFRN, 2009.
}

O trabalho de Teixeira oferece contribuições para os pesquisadores que se dedicam tanto ao estudo da cidade no período republicano, quando aos que se dedicam ao período imperial e colonial. $O$ autor analisou não somente as mudanças na estrutura física das cidades nesse recorte temporal, mas também examinou as transformações dos usos e significados do solo urbano no período estudado, compreendendo como os atores sociais relacionavam-se e davam sentido a esses espaços. Trata-se de um trabalho de referência para entender conceitos como rossio, função urbana, vila, termo, foral, arruado, laudêmio, entre outros termos próprios das configurações espaciais da cidade em cada recorte temporal específico (Colônia, Império ou República).

Teixeira mencionou a questão do aforamento cobrado durante o período colonial, quando a forma de apropriação do solo dava-se por meio da concessão de sesmarias. Como o autor pretendeu trabalhar um período extenso, analisando doze cidades em um recorte de aproximadamente dois séculos e meio, algumas simplificações foram cometidas. O autor não se dedicou à realização de um histórico do aforamento, não comentando de forma aprofundada sobre a origem e implicações de tal instituto.

Teixeira concluiu seu estudo sobre as formas de apropriação do solo urbano destacando que os patrimônios leigos impõem-se definitivamente no processo de expansão urbana de todas as localidades no século $X X$, mesmo naquelas em que a Igreja ainda possui terras. Ocorreu, assim, o que o autor denominou de imposição de um sistema mercantil de apropriação do solo urbano, embora a presença do foro em certas áreas, sobretudo eclesiásticas, relativizasse a intensidade desse processo.

O trabalho de Rubenilson Teixeira é, sem dúvida, referência para quem estuda o instituto do aforamento, seja em áreas urbanas, rurais ou suburbanas, já que foi o primeiro, e um dos únicos trabalhos, que mencionou a questão do aforamento para a realidade norte-rio-grandense, mesmo não se 
dedicando a entender esse instituto na realidade natalense. $\mathrm{O}$ autor perseguiu vários objetivos em seu livro, não tendo a pretensão de fazer um estudo detalhado sobre a questão do aforamento urbano, como elucidou ao longo da obra. Assim, as brechas existentes em sua argumentação são reflexos de suas pretensões, o que evidencia a necessidade de estudos que se dediquem a analisar esse instituto.

Outras obras gerais, como a do sociólogo Itamar de Souza ${ }^{36}$, também abordaram o bairro Cidade Nova. Entretanto, a abordagem de Souza não passou de considerações resumidas, em muitos casos, a uma mera descrição do bairro, em que o autor citou alguns equipamentos existentes, destacando a construção de casas de membros da família Albuquerque Maranhão, discorrendo sobre algumas denominações de ruas e avenidas, e citando alguns locais de socialização existentes, como o Aeroclube e o Polígono de Tiros Deodoro da Fonseca. O contexto em que o bairro Cidade Nova foi criado é resumido a um momento de desenvolvimento econômico do estado e da cidade, enfatizando a importância de Pedro Velho como idealizador não só do terceiro bairro, mas de todas as reformas de modernização vivenciadas por Natal no período.

Souza possuiu em sua obra um recorte temporal amplo, buscou oferecer uma publicação, lançada em 2008, que contasse a história da cidade desde a sua fundação até o século XXI. Dessa maneira, observa-se que o bairro Cidade Nova não era o seu objeto principal. A obra de Souza pode ser utilizada como referência inicial para a problematização da história urbana da capital norterio-grandense, pois o autor apontou em seus capítulos vários documentos que são fundamentais para a pesquisa de diversas temáticas sobre a cidade de Natal.

Os historiadores do Departamento de História da UFRN também já desenvolveram trabalhos sobre a história urbana de Natal. O grupo de pesquisa Os espaços na modernidade, criado em 2008 e coordenado pelo professor Raimundo Arrais, é uma

\footnotetext{
${ }^{36}$ SOUZA, Itamar de. O terceiro bairro de Natal: Tirol e Petrópolis. In: Departamento Estadual de Imprensa, 2008.
}

referência para os pesquisadores que estudam diversos temas relacionados à capital norte-riograndense no período da Primeira República. Os alunos e pesquisadores vinculados ao grupo desenvolvem trabalho intenso de coleta e análise de fontes até então pouco ou nada trabalhadas pela produção local. Um exemplo desse esforço, fruto de três anos de pesquisa, é o livro intitulado $A$ Intendência e a cidade: fontes para o estudo da gestão da cidade do Natal (1892-1919) ${ }^{37}$. Tal obra foi resultado de um trabalho exaustivo de localização, coleta, digitalização, reunião e análise de várias resoluções municipais publicadas no início do século $\mathrm{XX}$, que estavam dispersas em jornais e livros de leis e decretos do estado.

Observadas em conjunto, as resoluções permitem a percepção do significado que o espaço público da cidade vai assumindo para os administradores no período estudado. Embora os pesquisadores do grupo, como pode ser observado no estudo introdutório da obra, compreendam que a legislação não representa a forma como essa cidade foi praticada e entendida por toda a população, ou seja, não corresponde aos usos dos sujeitos, eles entendem que os temas das resoluções podem indicar o ideal de cidade que os grupos dirigentes possuíam. Para esses pesquisadores, as resoluções são espécies de "termômetro das preocupações que moviam o Conselho da Intendência"38. Os pesquisadores também problematizaram essa relação entre lei e prática, demonstrando, muitas vezes, que os próprios intendentes estavam envolvidos em relações pessoais com o patrimônio público, que implicavam no descumprimento de resoluções.

O pesquisador Renato Marinho Santos, também membro do grupo, em sua dissertação de mestrado, Natal, outra cidade!:o papel da Intendência Municipal no desenvolvimento de uma nova ordem urbana (1904-1929) ${ }^{39}$, analisou o papel da

\footnotetext{
${ }^{37}$ ARRAIS, Raimundo; ARRAIS, Raimundo; ROCHA, Raimundo Nonato Araújo; VIANA, Hélder do Nascimento (orgs). A Intendência e a cidade: fontes para o estudo da gestão da cidade do Natal (1892-1919). Natal: Editora da UFRN, 2012. 38 Ibidem, p. 10.

${ }^{39}$ SANTOS, Renato Marinho Brandão. Natal, outra cidade!:o papel da Intendência municipal no desenvolvimento de uma
} 
Intendência na formação de uma nova ordem urbana em Natal e indicou, no segundo capítulo, a relação entre intendentes e aforamento urbano, citando que vários intendentes foram foreiros de terrenos em Cidade Nova. O estudo de Renato Santos é fundamental para auxiliar os pesquisadores da área no conhecimento dos indivíduos que ocuparam o Conselho da Intendência Municipal durante o início do século $X X$, ajudando, assim, na análise das relações de poder que permearam a o processo de ocupação da cidade.

Outra publicação desse grupo de pesquisa que também é fundamental para pensar as mudanças vivenciadas em Natal durante o período da Primeira República é a obra O corpo e a alma da cidade: Natal entre 1900 e 1930, escrita por Raimundo Arrais, Alenuska Andrade e Márcia Marinho, publicada em $2008^{40}$. Esse livro problematizou questões referentes à modernização da cidade entre o final do século XIX e as primeiras décadas do séc. $\mathrm{XX}$, estudando, como o título sugere, não somente as mudanças físicas vivenciadas pela cidade em seu "corpo", mas também as transformações nas formas das pessoas se relacionarem com os espaços, investigando as novas sensibilidades e representações, as modificações na "alma" dessa cidade, em meio às mudanças materiais.

Como exposto, os trabalhos produzidos pelo grupo de pesquisa Os espaços na modernidade serviram como caminho para pensar as transformações urbanas ocorridas em Natal no início do século XX. Deve-se enfatizar o esforço desses pesquisadores, que pesquisaram em vários arquivos da cidade e de outros estados, e, em meio a arquivos de difícil acesso, acervos desorganizados e documentos despedaçados, fizeram um trabalho de digitalização, digitação e análise de fontes até então pouco utilizadas, como as resoluções municipais, registros cartoriais, entre outras fontes, de modo a

nova ordem urbana (1904-1929). Dissertação (Mestrado em História). Programa de Pós-Graduação em História, Universidade Federal do Rio Grande do Norte (UFRN), Natal, 2012.

${ }^{40}$ ARRAIS, Raimundo; ANDRADE, Alenuska; MARINHO, Márcia. O corpo e alma da cidade. Natal: EDUFRN, 2008. facilitar o trabalho de pesquisadores que, no futuro, interessem-se pela temática em questão.

Uma característica que perpassou quase todas as obras comentadas que se referiram à construção do terceiro bairro oficial de Natal foi a abordagem desse território como uma novidade, como fruto do cenário de prosperidade e remodelação urbana propiciado pelo contexto do período e como território exclusivo dos mais abastados e influentes. Muitos trabalhos não atentaram para as continuidades, para a presença, nessa região, de indivíduos populares, sujeitos que não integravam os grupos mais influentes da capital, mas que foram fundamentais para concretizar o novo território. Esses autores não problematizaram, portanto, as ambivalências existentes no processo de apropriação e uso do solo urbano em Cidade Nova ${ }^{41}$.

\section{Considerações finais}

Com base nas obras até então discutidas, observa-se que, assim como no cenário internacional, a história urbana brasileira e natalense foi estudada principalmente por arquitetos e urbanistas, tendo, pois, uma maior preocupação com temáticas referentes a projetos urbanísticos e a estudos das dimensões técnicas da paisagem da cidade.

Em relação à produção local que faz referencia ao bairro Cidade Nova, constatou-se que a maior parte dos trabalhos reproduz elementos da narrativa cascudiana presentes em História da Cidade do Natal. Assim, nesses trabalhos, Pedro Velho de Albuquerque Maranhão é sempre enfatizado enquanto precursor não só da idealização do bairro, mas de todas as reformas ocorridas na cidade no início do século $\mathrm{XX}$, sustentando-se, pois, o mito do herói republicano presente desde as primeiras narrativas elaboradas sobre a história do estado.

\footnotetext{
${ }^{41}$ Para uma análise mais aprofundada sobre a permanência desses populares em Cidade Nova e de outras continuidades existentes no terceiro bairro de Natal, ver: SIQUEIRA, Gabriela Fernandes de. Cidade Nova ou Cidade das Lágrimas?:a construção do terceiro bairro oficial de Natal no início do século XX. Oficina do Historiador, Porto Alegre, v.7, n.1, p. 63-68, jan/jun. 2014.
} 
Apesar de algumas obras apontarem a criação do bairro Cidade Nova como símbolo dos grupos dirigentes que ocupavam o poder local na racionalidade republicana, muitos trabalhos continuaram citando a construção do novo bairro apenas dentro de um contexto de reformas materiais, fruto da prosperidade econômica que o estado vivenciava no período. Outros trabalhos, embora elenquem o problema do político, não aprofundaram a relação entre esses grupos dirigentes e a ocupação do terceiro bairro, limitando essa questão apenas à citação dos nomes de figuras importantes que construíram habitações em Cidade Nova. Entretanto, alguns autores, como Renato Santos e Siqueira, apontaram indícios para se entender a complexa relação entre poder político e patrimônio público. O estudo da relação entre domínio e exercício da lei, ou seja, o cruzamento das legislações municipais e estaduais com outros tipos de fontes, como matérias de jornais e cartas de aforamento, por exemplo, podem ajudar a compreender as disparidades existentes entre a cidade idealizada, planejada, e a cidade real, praticada, concretizada.

\section{Referências}

AMORIM, Edgar Carlos de. Teoria e prática da enfiteuse. Rio de Janeiro: Editora Forense, 1986.

ARRAIS, Raimundo; ARRAIS, Raimundo; ROCHA, Raimundo Nonato Araújo; VIANA, Hélder do Nascimento (orgs). A Intendência e a cidade: fontes para o estudo da gestão da cidade do Natal (18921919). Natal: Editora da UFRN, 2012.

ARRAIS, Raimundo. Do alto da torre da matriz, acompanhando a procissão dos mortos: Luís da Câmara Cascudo, o historiador da cidade do Natal. Espacialidades, Natal, v. 2, n. 1. 2009.

ARRAIS, Raimundo; ANDRADE, Alenuska; MARINHO, Márcia. O corpo e alma da cidade. Natal: EDUFRN, 2008.

BICALHO, Maria Fernanda. A cidade e o império: o Rio de Janeiro no século XVIII. Rio de Janeiro: Civilização Brasileira, 2003.

BRESCIANNI, Maria Stella. História e Historiografia das cidades, um percurso. In: FREITAS, Marcos Cézar de (org.). Historiografia brasileira em perspectiva. São Paulo: Contexto, 2010.
BUENO, Almir de Carvalho. Visões de República: idéias e práticas políticas no Rio Grande do Norte (1880-1895). Tese (Doutorado em História). Programa de Pós-Graduação em História, Universidade Federal de Pernambuco (UFPE), Recife, 1999.

CASCUDO, Luís da Câmara. História da Cidade do Natal. Natal: Editora da UFRN, 2010.

$\overline{\text { UFRN, } 2008 .}$.

Vida de Pedro Velho. Natal: Editora da

CONGOST, Rosa. Tierras, leyes, história: estúdios sobre lagran obra de lapropiedad. Barcelona: Crítica, 2007.

ENCONTRO NACIONAL DA ANPUR, 2007, Belém. Anais eletrônicos do XII Encontro Nacional da Anpur. Disponívrl em $<$ http://www.anpur.org.br/inicio/index.php/2012-09-1313-08-43/anais>. Acesso em: 23 dez. 2012.

FERREIRA, Angela Lucia et.al. Surge et Ambula: a construção de uma cidade moderna (Natal, 18901940). Natal: Editora da UFRN, 2006.

GROSSI. Paolo. A propriedade e as propriedades na oficina do historiador. In:_. Historia da propriedade e outros ensaios. Rio de Janeiro: Renovar, 2006.

LEPETIT, Bernard. Proposições para uma prática restrita da interdisciplinaridade. In:_. Por uma nova história urbana. Organização: HelianaAngotti Salgueiro. São Paulo: Edusp, 2001.

LIMA, Pedro de. Natal século XX: do urbanismo ao planejamento urbano. Natal: EDUFRN, 2001.

MONTEIRO, Charles. Entre história urbana e história da cidade: questões e debates. Oficina do Historiador, Porto Alegre, v.5, n.1, jan/jun. 2012.

PECHMAN, Robert; RIBEIRO, Luís César de Queiroz (orgs.). Cidade, povo e nação: gênese do urbanismo moderno. Rio de Janeiro: Civilização Brasileira, 1996.

PEIXOTO, Renato Amado. Verbete - Alberto Maranhão. In: ABREU, Alzira de (org.). Dicionário histórico-biográfico da Primeira República. Rio de Janeiro: Editora da Fundação Getúlio Vargas, 2012. Disponível em: < http://cpdoc.fgv.br/dicionarioprimeira-republica>. Acesso em: 26 maio 2015.

PINO, Jean-Luc. Le monde desvillesau XIX siècle. Paris: Hachette, 1991.

RONCAYOLO, Marcel. Les grammaires d'une ville. Essai sur la genènese des structures urbaines à Marseille. Paris: Éditions de l'EHESS, 1996.

SALGUEIRO, HelianaAngotti (org.). Cidades capitais do século XIX: racionalidade, cosmopolitismo e transferência de modelos. São Paulo: Editora da Universidade de São Paulo, 2001. 
SANTOS, Renato Marinho Brandão. Natal, outra cidade!:o papel da Intendência municipal no desenvolvimento de uma nova ordem urbana (19041929). Dissertação (Mestrado em História). Programa de Pós-Graduação em História, Universidade Federal do Rio Grande do Norte (UFRN), Natal, 2012.

SCHORSKE, Carl. A ideia de cidade no pensamento europeu: de Voltaire a Spengler. In:

Pensando com a história. São Paulo: Companhia das Letras, 2000.

SILVA, Luís Octávio da. História urbana: uma revisão da literatura epistemológica em inglês. EURE (Santiago)- Revista latinoamericana de estudios urbano regionales, Santiago, v. XXVIII, n.83, 2002.

SIQUEIRA, Gabriela Fernandes de. Cidade Nova ou Cidade das Lágrimas?:a construção do terceiro bairro oficial de Natal no início do século XX. Oficina do Historiador, Porto Alegre, v.7, n.1, p. 63-68, jan/jun. 2014.

O homem que pintava a cidade por meio de palavras: cenas urbanas natalenses construídas a partir das crônicas de Henrique Castriciano. Cordis - Revista Eletrônica de História Social da Cidade, São Paulo, n.10, p. 93-131, jan/jun. 2013.

Por uma "Cidade Nova": apropriação e uso do solo urbano no terceiro bairro de Natal (1901-1929). Dissertação (Mestrado em História). Programa de Pós-Graduação em História, Universidade Federal do Rio Grande do Norte (UFRN), Natal, 2014.

SOUZA, Itamar de. O terceiro bairro de Natal: Tirol e Petrópolis. In: Nova História de Natal. 2ed. Natal: Departamento Estadual de Imprensa, 2008.

VIDAL, Laurent. Tendances recentes de La recherche sur l'histoire du Brésil urbain. Éléments pour um bilan: 1990-2003. Histoire urbaine, n.12, 2005. 